\title{
The Development of a Framework for Green Information Technology Implementation in South African Organisations
}

\author{
TIhalefo Petterson Moyo \\ Sam Lubbe \\ Rembrandt Klopper \\ Jan Meyer
}

\section{Abstract}

This study was primarily an empirical investigation in the field of Information Technology (IT) on how Green IT is implemented by South African organisations. The relative lack of Green IT framework in ensuring successful Green IT implementation for South African organisations was the primary impetus of this study, which advanced this important, but neglected area of Green IT. The study highlighted the pitfalls of Green IT implementation and adopted a realism problem solving approach using an empirical solution to find answers within the field of Green IT implementation in South African organisations. The study focused on the development of Green IT framework for South African organisations. In this regard, an in-depth qualitative research methodology was undertaken through semi-structured interviews to gather data in order for South African organisations to implement Green IT effectively. This study unveiled and filled the growing gap of Green IT implementation by developing a new chain of thought. This was done by creating a Green IT framework and operational workflow.

Keywords: Environmental sustainability, E-Waste, Green Computing, Green ICT, Green IT and Green technologies. 


\section{Introduction}

Society's reliance on Information and Technology (IT) has increased tremendously over the years. Unfortunately, the growth of an IT sector is contributing to increased human impact such as pollution, increased energy consumption and electronic waste that negatively affects the environment resulting in the phenomenon climate change. This climate change challenges the survival of the present and future generation (Molla 2009). It is acknowledged that if humans do not decrease the level of toxic waste and pollution released into the atmosphere, the earth may no longer be a sustainable living environment for any creature (Chow \& Chen 2009:136). In recent years IT is gradually playing a serious role in altering and producing commercial opportunities, since technology is likely to create sustainable businesses and societies with grim and green economies. Therefore, the concern regarding the increase in climate change has been unprecedented, and requires solutions for environmental sustainability (Uddin \& Rahman 2012:4079 - 4084). Empirical evidence indicates that organisations have been influenced by market forces, legislation and ethical issues to minimise the harmful impact on the environment. Conversely, to tackle the impact on the environment, society and business need to find ways to reduce the impact on the environment in order to achieve the ultimate goal of environmental sustainability. In this regard, Green IT plays a pivotal role because it is intended to minimise the negative impact of IT operations on the environment by designing, manufacturing, operating and disposing of computers and computer related products in an environmentally friendly manner (Murugesan 2008:25 - 26). The aim of this paper is to provide contextual background on Green IT for personnel and management, then develop a Green IT framework to guide the implementation of appropriate Green IT practices for South African organisations.

\section{Background and Context}

The concept of Green IT emerged in 1992 when the United States Environmental Protection Agency launched the Energy Star programme. The intention of this launch was to ensure a voluntary labelling programme to segregate computers, monitors and equipment based on their energy efficiency and help the organisations in saving money and reduce on greenhouse gas (GHG) emissions through the identification of products that offer greater 
energy efficiency. It is for this reason that Green IT is receiving considerable interest from organisations that realised that going green is in their best interest to curb the negative environmental impact (Nayab 2011). Green IT adoption plays an important role in organisations because it encourages new ways of reducing atmospheric pollution, implementing higher efficiency and alternative power generation systems, discovering different data servers, manufacturing recyclable computers and the use of less hazardous materials in technological revolution. This offers economically viable solutions for organisations that conserve energy and protect the environment (Murugesan 2013). In South African context, the highest contributor to GHG emission is the Energy sector which contributes about $85 \%$ to the total GHG emission, followed by Industrial process and Product use estimated at about 8\%, Agriculture, Forestry and other Land Uses projected at $4 \%$ and Waste contributing estimated at about 3\%. This has resulted in South Africa being counted amongst the highest emitter of GHG emissions. Previous studies also highlight that IT industry is accountable for 3\% of global emissions which is approximately equivalent to the aviation industry because of its rate of energy consumption, and projected to increase by $6 \%$ during 2020. Should the existing trend continue consistently it will grow more than predicted by 2020 , thus posing unmanageable worries and creating a new climate of uncertainty (Gartner 2008). This is something of a pitfall, therefore, organisations are starting to realise the benefits of using Green technologies in order to reduce carbon footprint and improving their business performance (Murugesan 2013). Going green implies seeking a resolution to reduce the overall energy consumption due to developing technology of corporations. Power grids have forced technology companies to design and manufacture energy efficient products, that is technology indispensable to enterprises and consumer demand. As such, moving towards Green IT implementation has the potential to conserve energy and protect the environment leading to substantial saving of money for the organisations.

\section{Statement of the Problem}

IT operations inherently have negative effect on the environment in the sense that they consume large amount of electricity and the disposal of IT equipment (e-Waste) contains hazardous materials that are unsafe to the environment that causes the release of GHG emissions in the atmosphere and contributes to 
global warming and climate change. However, little research has been done to examine the potential of Green IT. A neglected area in the field of this study is that many organisations are painstaking about being green but they are not certain how to go about it (Jenkin, Webster \& McShane 2011:34). Despite Green IT having existed for several years and beneficial for organisations, it still suffers drawbacks in terms of adoption (Gartner 2008). In light of these concerns, there is a strong need to develop a Green IT framework and strategies to address the wider environmental and health issues in organisations.

\section{Research Objectives and Questions}

The aim of this study was to develop a framework for Green IT implementation and demonstrate that the results of Green IT, if not adopted leads to escalating cost of energy, depletion of natural resources and increase in concern for the environment by the general population.

\section{The objectives of the study are to:}

- Provide contextual background on Green IT.

- Determine the impact of IT related products on the Environment and Health.

- Describe the development and implementation of Green IT into business strategic plans.

- Critically evaluate the approach to Green IT.

- Determine measures that can be used by organisations to implement Green IT and create a sustainable environment.

- Develop a framework for Green IT implementation.

\section{These aims seek to provide answers to the following questions:}

- What methods of technology can be used to reduce pollution and contribute to the optimal use of renewable energy?

- What method can be used to reduce energy consumption as a result of green technology?

- What approach can be used in the design, production, operation and disposal of IT products in a manner that is not harmful to the environment?

- What strategies can be used to help IT contribute to environmental solutions? 
- What sources can be used to determine the impact of adoption of strategic Green IT towards creating a sustainable environment?

\section{Overview of the Literature}

The primary impetus of the literature review is to develop a Green IT framework for South African organisations, with the objective of developing a theoretical framework that seeks to ensure successful Green IT implementation in the organisations.

\section{The Effect of GHG Emission}

The current high level of energy consumption is contributing to GHG, which is the main cause of climate change. A challenging concern for climate change is that, if humans continue to pump extra carbon dioxide into the atmosphere, this will cause an imbalance in GHG emissions effect and eventually this will affect the weather patterns (Borggren et al. 2013:126). Some scientists suggest that global warming beyond $2^{\circ} \mathrm{C}$ carries the risk of irreversible harm to human wellbeing and development prospects across all countries. They warn that the earth's climate is on track for $4^{\circ} \mathrm{C}$ of warming, and this scenario is linked to greater hunger, species loss and homelessness caused by rising sea levels. This phenomenon of environmental impact is recognized because the ozone layer cannot be repaired once the damage is done (Korte, Lee \& Fung 2012:2). However, there has been some disagreement concerning global warming, some experts are of the opinion that there is no scientifically binding mechanism for carbon dioxide causing climate change because the global temperatures have always been changing despite carbon increases. They state that the earth is much older than the human race and has never been static (Roosa \& Jhaveri 2009). This argument continues despite the aftermath of carbon emission being significantly high because of computer electricity usage. Research studies indicate that GHG emissions in the atmosphere absorb and emit radiation which is a fundamental process that causes the greenhouse effect (Harmon \& Auseklis 2009:1709). A major concern is that carbon emission is one of the heaviest gas molecules in the atmosphere which stays low, hugging the grounds and allowing the plants to photosynthesize and its biggest problem is that it is getting higher into the atmosphere thereby creating GHG emission effects. However, climatologist provides a different perspective on this matter 
and indicate that in actual fact the planet has cooled by 0.7 degrees. Therefore, there is no scientifically binding mechanism for carbon causing global warming. They believe that the public is being deceived through propaganda. According to them, there is no compelling evidence that the observed warming is caused by man. They are of the opinion that temperature records have been manipulated to affect the overall picture of rising temperatures (Beluz, Plumer $\&$ Resnick 2016). The main argument is that climate change is political imperative rather scientific. Therefore, it is hard to avoid the impression that the public is being told less than unvarnished truth. According to them, manmade climate change is a scam and alarmists are making false predictions to create hysteria and bring about carbon taxes (Bourke 2014). On the other hand, some of the scientists argue that since the effects of increased carbon dioxide on the environment is unknown, action is required to limit the emission until its effect is better understood. So, the time of inaction has passed and the time of initiative is upon businesses. There is a consensus that Green IT adoption is the ultimate solution to reduce this evil beast called carbon by utilising green technologies (Campbell, Ratcliffe \& Moore 2013:127). These particular aspects has resulted in many organisations incorporating Green IT agenda in their businesses, but are often constrained to the traditional IT environment.

\section{The Importance of Carbon Reduction}

Research indicates that during the past century the pace of warming has accelerated causing new problems to surface that emphasize the ultimate fragility of the planet's ecosystems. In the context of this study, technology has been regarded as a major contributor to GHG emissions and environmental pressures. In light of this concerns, this has led to organisations seeking solution to reduce carbon emission (Murugesan 2008:25). However, a contradictory notion exist on carbon emission. Some of the experts believe that no matter what action is taken today, the consequences of increasing carbon levels will continue to plague the earth for generations to come. Therefore, the time has come for organisations to refocus their resources towards finding solutions that will reduce or eliminate carbon emissions. Organisations have accepted varying degrees of technology to drive green programme, but they have failed to adopt large-scale implementation of these initiatives. Moreover, they have failed to identify the role that IT can play in implementing and optimizing these green initiatives that offers the potential to save the planet 
(Roosa \& Jhaveri 2009). Despite the limited research currently existing on the benefits of driving IT for business innovation, the preventative measures of ecological change are desperately needed to avert catastrophic climate change.

\section{The Challenge of Electronic Waste}

The quantities of Electrical and electronic equipments put on the market show an increasing trend for the industrialised and developing countries. South Africa generates an estimated 2, 000, 000 tons of e-waste annually which are sent to landfills and contain poisonous substances that can leach from decomposing waste into the environment (Advanced Tropical Environment 2012:1720). This statement simply highlight that e-Waste is the fastest growing problem globally and has become a topic of concern for electronic industries because of the rapid accumulation of unused (obsolete) computers which have become part of the growing stream in landfills (Kiddee, Naidu \& Wong 2013: 1237). The problem that arises now is that these toxic and hazardous materials contained in e-Waste are contributing to environmental pollution and have the the potential to cause brain damage, allergic reactions and cancer if they are inadequately treated and disposed of (Petzer, McGibbon \& Brown 2011:331). The Basel Convention developed an amendment to ban the export of hazardous waste for disposal to the developing countries. However, the import of e-waste significant volumes are still entering the country illegally (Schiffman 2015). In the same light, research studies suggest that some computers are intentionally designed for short life cycles and use materials and processes that obstruct recycling efforts with the objective of requiring consumers/ organisations to purchase new products (Binns et al. 2006:10). This has resulted in less than $10 \%$ of e-waste produced being reused or recycled. Concerns have arisen that majority of the e-waste is inappropriately disposed of in landfills. The underlying reason for this concern, is that many organisations don't know how dispose of electrical equipments, and they don't have convenient access to recycling causing a range of environmental problems (Gaidajis Angelakoglou \& Aktsoglou 2010:197). The concept e-waste recycling leaves many unresolved questions related to human exposure to toxins during recycling. Currently there is uncertainty on whether e-waste recycling practices eliminate all human exposure to e-waste toxins and the exposure rate is unknown. Moreover, limited evidence currently exists demonstrating the method by which modern landfills leak into the environment. This particular aspect 
suggest that disposed e-waste should be reused/recycled and managed with caution because it involves significant risks. There has been some debate amongst scientist about the risk posed to humans by disposing of e-waste in landfills because people dismantling e-waste show significantly higher levels of brominated flame retardants in their blood. However, the bottom line is that recycling methods that are most beneficial for preventing adverse health effects should applied to preserve the environment (Binns et al. 2006:19).

\section{The Effect of Power and Energy Consumption}

The main disadvantage of IT is that it consumes global energy twenty four hours a day causing the release of carbon dioxide into the atmosphere resulting in harm to the environment and impacting business negatively (Campbell, Ratcliffe \& Moore 2013:127). This scenario of energy consumption takes place even though IT equipment are not in use. Research studies indicate that the consumption of IT use is continually increasing at a rapid pace causing indisputable rise in carbon levels and creating a challenge for businesses, thus requiring immediate attention (Lee, Park \& Trimi 2013:631). This escalating energy consumption is caused by expansion of data centres and is gradually increasing to run the IT infrastructure resulting in environmental concerns. Unfortunately, a lot of power used by IT is simply wasted because many servers are not doing any useful work and still use $60 \%$ of their maximum power load when they idle ( $\mathrm{Li}$ 2017:20-23). While energy prices is growing internationally, the operational cost of data centres continue to rise gradually (Murugesan, 2008:28). Given the rise of data centres costs it means that designing servers that conserve energy in proportion to work performed is a need, which implies Green IT adoption. In other words, IT can contribute to major energy saving and help organisations save money, comply with corporate strategy and meet sustainable targets (Dao, Langella \& Carbo 2011:2). By the way, there is a growing body of evidence that suggests that IT organisations can green up their energy procurement and recycling practices. Changing the traditional way in which organisations do business and utilizing IT can benefit the environment. However, the cost reduction in energy savings increased by going green is not always enough to counterbalance the initial upfront exchange costs. The theory underpinning Green IT adoption is that IT can assist in driving more efficient and greener processes thereby generating substantial saving (Chou 2013:236). On the other hand, there is a renewal 
energy deliberation about the constraint and opportunities linked with its use. In many instances, renewable electricity production, from sources such as wind power and solar power is sometimes criticized for being inconstant or irregular despite the market for renewable energy technologies continuing to grow. This suggest that a fresh approach on IT and power is needed and organisations should be proactive to find ways to become more energy efficient in order to reduce carbon foot print (Widjaja, Mariani \& Imam 2011). In this regard, IT managers should have ecological concerns at the top of their plan in purchasing of IT equipments and help their organisations to be more environmentally aware in their use of technology (Li 2017:20 - 23).

\section{The Effect of Corporate Governance on the Business}

Organisations are becoming aware of their responsibilities towards the environment because of their effect of gas emissions, toxic waste materials and increased energy consumption resulting in adverse environmental impact (Borggren et al. 2013:127). In line with this statement, environmental stewardship has emerged over the years to reduce GHG and carbon footprint that eventually results in climate change. As a result, organisations are playing a significant role in the protection of the environment to improve their business performance (Brooks, Wang \& Sarker 2012:16). The Kyoto Summit brought 160 nations together in an effort to reduce carbon emissions and device ways to mitigate climate change. However, at Kyoto the success of the negotiations depended on the individual nation's willingness to comply with the treaty (Petzer, McGibbon \& Brown 2011:332). Research studies reveal that skepticism is rising that an agreement will be reached on global climate treaty to replace the Kyoto Protocol (Schiffman 2015). The bottom line is that the result of the Kyoto Protocol has been mixed and in most cases ineffective (Roosa \& Jhaveri 2009:38). This is because the Kyoto Protocol is regarded by critics as a socialist scheme designed to suck money out of rich countries. Therefore, its compliance has had the opposite effect because its recommendations are not mandated by law. In this regard, there is a need for stricter environmental regulations to improve corporate image. Notably, there is lack of legislation on the other hand restricting the hazardous substance, and as a result, carbon emission remains unregulated and e-waste is growing at an unprecedented rate causing significant adverse impact on the environment (Hanne 2011:425). The European Union Waste and Electronic Equipment 
directive enforces legal obligations on the producers, importers and resellers of electronic equipment to dispose of, refurbish and recycle IT equipment in an ecologically sound manner to ensure minimum compliance (Campbell, Ratcliffe \& Moore 2013:127). However, despite these directives, there is inadequate legislation globally for effective e-waste management in both developed and developing countries (Kiddee, Naidu \& Wong 2013:1238). It evident that the regulation driving Green IT is inadequately enforced and is presenting a challenge including the Kyoto protocol. As a result, the developing countries have become a dumping ground of e-Waste because of the lack of legislation. It has now been suggested that businesses should dispose or recycle e-Waste in a safe and lawful manner. This simply implies that the development of new regulations and Green IT implementation is essential to respond to emerging issues of e-waste (Dittke 2009).

\section{The Effects of Sustainable Development and Environmental Sustainability}

Despite the increased popularity of the use of environmental sustainability, it continues to be questioned in light of the environmental degradation and climate change. Harmon and Auseklis (2009:1701-1712) explain that sustainable IT is everything that an organisation needs to do in ensuring that IT services deliver a superior value in order to attain market position and the ability to survive. Creating a sustainable business does not only benefit the planet, but also impacts people and local communities where business is conducted (Gartner 2008). This suggests that ecological sustainability is a solution to environmental and social problems because the natural environment is deteriorating in unrecoverable manner from the growing impact of human economic activity (Jenkin, Webster \& McShane 2011:17). Sustainability is the key to prevent or reduce the effect of ecological issues. The immediate and long term impact of environmental sustainability is economic growth which is a solution to environmental and social problems through Green IT adoption.

\section{The Effects of Green IT Strategies on Businesses}

The literature review suggests that a holistic and all-inclusive Green IT strategy should be developed by organisations to minimise the negative impacts of the ecosystem. In context, the fundamental IT strategy should be aligned with the 
business strategy to improve organizational competitiveness and managing environmental aspects (Cai, Chen \& Bose 2013:493). However, it is shocking to note that organisations have not realized the impact of climate change in order to aggressively tackle it through the development of Green IT strategy. Sustainable business and green economics can be created by technology because IT is enabling technology to have an impact on all sectors of life and has the potential for accomplishing green economic long-term growth and universal sustainability (Uddin \& Rahman 2012:4078). The current consenus is that green economy improves human wellbeing and social equity, while considerably reducing environmental threats and environmental shortages (Welfens \& Lutz 2012:156). However, it is believed that it does not favour political viewpoint but works to minimise disproportionate depletion of natural capital. Green economy is complex in terms of policy prescriptions especially the subject of universal negotiations. Despite the green economy evolving as an important concept, it is also controversial. There is no scientific agreement on how to achieve a green economy, nor is there an international agreement on what it means and how to move towards it. The developing countries want green economy concept to be placed within the sustainable development framework of the Rio Summit and not to replace it. While experts acknowledge the positive aspects of developing the green economy concept they also point to related risks. Green economy utilizes one size fits all approach by treating all countries in the same manner and this may lead to failures either for the environment, development or both. It is also inappropriately used by countries for trade protection purposes particularly rich countries to justify unilateral trade measures against the products of developing countries, or to impose standards that have not been agreed upon. By coincidence, this pressurizes the affected developing countries to take on one dimensional environmental measures rather than sustainable development policies. However, there is a current debate on these issues, of which many believe that the environmental crisis is a result of market failures, which have generated resource depletion, pollution and environmental crisis. In general, green economy has the potential to reduce carbon emissions, enhancing energy and resources efficiency.

\section{The Impact of Green Design}

Green design means the designing of efficient and ecologically sound computers, servers, cooling equipment and data centres (Chou \& Chou 2012:448). In 
the same light, Adhikary (2008:22) sees such a design for green as a major factor in achieving Green objectives despite the design systems having constraints. Thus, it is imperative for organisations to focus on energy efficiency methods throughout the manufacturing of IT products (Brooks, Wang \& Sarker 2012:34). Investors and consumers are beginning to request more disclosures from companies with regard to their carbon footprint as well as their environmental initiatives and attainments. They have started discounting share prices of companies that poorly address the environmental problems they create. As a result, many businesses have begun showing their environmental credentials (Murugesan 2008:26). Going green can be an attractive goal to gain goodwill and consumer support, but unless green improvements are economically viable, it can put a business at a competitive disadvantage. Many studies suggest that information systems should be studied from conceptualization to development throughout the operations, in order to acquire deep understanding of IT management practices (Berghout, Nijland \& Powell 2011:755). This entails taking into consideration material extraction, production, and use, transport and end life cycle of the IT product when determining green technology and environmental impact. Research studies indicate that ecologically comprehensive IT products should not be hazardous to the health of people or animals, nor cause any damage to the environment during manufacture, use or disposal, nor lead to consuming energy, nor unnecessary waste due to short life span (Vereecken et al. 2010). In essence, efficient IT is equal to Green IT, which is genuine beneficial by-product of the primary goal that delivers the right amount of IT at the right time. Moreover, ISO 14001 provides a guideline to manage environmental footprint, consequently resulting in the best practice for Green IT programmes.

\section{Research Methodology}

The essence of research generally requires a particular methodology before getting data or analysing the data. Therefore, research methodology is generally expressed as the ways in which data are collected (McNabb 2010:41).

\section{Population}

In view of literature, population is any complete group of entities that share some common characteristics. It provides a group of elements from which a 
researcher samples and likely to generalise (Clarke 2011:102). The population of the sampling method selected for this study was non-probability sampling which had elements identified as known and not zero probability from eight South African organisations. This means that the sample was drawn in a way that does not give every participant of the inhabitants a known chance of being nominated.

\section{Sampling Strategy}

The identification of the research sample must depend on the research questions that the researcher wants to be answered. This means that the researcher must ensure that the sample include people that will give the kind of information he/she is seeking (Leedy \& Ormrod 2013:279-284). In the context of this study, purposive sampling was chosen in relation to the research design and methodology because the researcher believed that this technique would yield a representative sample. The selection criteria for inclusion in this research study was IT professionals (15) and management (5) who articulate experience, as it relates to the Green IT phenomena to be investigated from eight South African companies.

\section{Data Collection}

The phenomenon of data collection is described as how the researcher obtains empirical data that will be used to answer research questions. In theory, the method of data can be tests, questionnaires, interviews, focus groups, observations and existing secondary data (Christensen et al. 2011:2015). The data collection in this study was obtained from primary sources through interviews with IT professionals and management at the selected companies. The interview development matrix was used to develop research interview questions. A semi-structured interview was then utilised using open ended questions, thereby allowing participants the freedom to control the pacing and subject matter of the interview. The rationale behind the usage of semistructured interviews is that it seeks to cover both factual and meaningful information, and participants had the opportunity to respond more elaborately and in greater detail. All interviews were recorded with the permission of the respondents being interviewed. After the interviews the recording was transcribed into computer files. The researcher recorded the information and 
made use of hand-written notes. Care was taken by the researcher to assure the respondents that they will not be identifiable, including their workplace in any subsequent report. Transcript of the interview was sent to the participant to get the participant's written acknowledgement for its accuracy or corrected copy. The participants were informed that once the final research report was written, the tapes from interviews would be destroyed.

\section{Data Analysis}

The initial stage in the analysis of data is the critical examination of the data itself (McNabb 2010:243). In theory, data analysis is an organised and fundamentally taxonomic process of arranging and classifying the data that have been collected. When data have been collected, it is the task of the researcher to analyse the collected data. This analysis of data requires a number of closely related operations such as establishment of categories, application of these categories to raw data through coding, drawing statistical inferences and correspondence analysis. In relation to coding, the operation is usually conducted through categories of data that are transformed into symbols and may be tabulated and counted. In this multiple case study, data analysis includes the data collected through interviews. The responses provided were analysed against the questions asked during the course of interviews and the literature review.

\section{Tests Used in the Analysis}

The following tests were used in the analysis of the results of this study:

- Descriptive statistics including means and standard deviations, where applicable. Frequencies were represented in tables or graphs.

- Chi-square goodness-of-fit-test: A univariate test, used on a categorical variable to test whether any of the response options were selected significantly more/less often than the others. Under the null hypothesis, it is assumed that all responses are equally selected.

- Binomial test: Tests whether a significant proportion of respondents select one of a possible two responses. This can be extended when data with more than 2 response options is split into two distinct groups. 


\section{Distribution of Gender and Qualification}

The employees were predominately males with $75 \%$ (15) while $25 \%$ (5) were females. However, preference was not given according to gender. This reflects that the participants in the IT industry are dominated by males. This may be due to the inconsistent application of the employment equity legislation across the industry. About 75\% (15) of them hold Diploma certificates while 25\% (5) hold degree/certificates. This indicates that majority of the participants are highly qualified and that education cannot be used as a differentiating factor, and working in the IT industry requires high level of education.

\section{Distribution of Time in the Company, Involvement in the Company and in the Position}

It was discovered that half of the participants served the company between five to six years and $25 \%$ (5) served between seven to ten years while the remaining $15 \%$ (3) served between 1 to 2 years and $10 \%$ (2) served for three to four years. This result indicates that IT personnel's length of service is sufficient to execute their tasks in their organisations. The majority of the participants $75 \%$ (15) occupy non managerial positions while $25 \%$ (5) occupy managerial positions. This means that most of the participants are probably field workers. In the same way, the majority of participants $75 \%$ (15) are involved in the company IT while the remainder 25\% (5) are involved in business and IT.

\section{Technical Optimisation to Address Ecological Issues}

The data below provide the view of the participants that the benefit for going green and using eco-friendly system for their companies is related to the following:

Green products purchase: The participants viewed purchasing green products that are energy efficient and environmentally friendly as essential for their companies to minimise harmful environmental impact. The selection of green products involves making trade-offs between environmental impact. The purchasing of green products is beneficial for the companies to reduce harm to the environment and provide a sense of environmental awareness. This lends support to previous findings in literature that the benefits of green products are 
expressed in terms of money, risk or brand. Therefore, it is essential for organisations to choose more energy efficient and environmentally friendly products that have Energy Star and Energy Star or Electronic Product Environmental Assessment Tool (EPEAT) ratings when buying IT products. This implies that organisations will save money and reduce the environmental impact because green products use less energy resources.

IM communication: The participants mentioned that they are utilising IM communication in order to reduce travelling because travelling contributes to environmental damage through carbon emission. Therefore, according to the participants, investing in IM communication has the potential benefits for their companies in reducing environmental harm. The use of telecommunication, teleconferencing and videoconferencing technology plays a vital role in carbon foot print reduction. This is consistent with Harmon and Auseklis (2009:1707) that ecological issues of IT products and service design need to be addressed to deal with atmospheric pollution. These suggest that the cars are consuming a lot of energy on the road thus causing environmental impact. However, IT can bring new hope to the organisations through shared information, online connection, electronic communication and video conferencing. These types of communication tools not only allow people far away from each other to work together, but they reduce environmental impact people would normally cause resulting from travelling.

Bio plugs: This was described by the participants as a method of technology utilised by their companies to reduce or minimise sensitive materials. This type of technology supports energy efficiency and helps in reducing the impact caused by IT products/equipments. This shows that efforts are being made by organisations to reduce consumption of energy by launching a programme in support of energy efficiency. It is acknowledged by Vine and Hamrin (2008:467) that the modern IT systems provide more computing power per unit $(\mathrm{kWh})$ thereby reducing energy consumption of computing power. Therefore, energy efficiency should be improved through the design and use of advanced technologies.

Printing reduction: This was viewed by the participants as a contributing factor to escalating business costs and thus contributing to high energy consumption. According to the participants, the reduction in printing will minimise 
environmental harm and will contribute significantly to the business profit margins. This confirms previous findings in the literature that printing contributes to increased carbon footprint. Thus, the reduction of printing will save trees and the ecosystem. This is because about $90 \%$ of paper comes from the trees and in most instances the trees are not sustainably harvested. This suggests that moving to a paperless system eliminates a large portion of waste in the workplace and has the potential to save money and reduce on carbon footprint. Therefore, organisations should consider distributing information electronically rather than printing it. This implies that organisations should invest in green strategies to reduce existing energy consumption by configuring printers and using less paper and ink.

Use of UPS and generator: This was described by the participants as a measure to provide emergency power to a load when the input power source/main fails. They felt that their companies should find alternative clean resources to improve energy efficiency through the design and use of advanced technology to achieve environmental sustainability. Then again, they also viewed the use of Uninterruptible power supply (UPS) and generator preventing possible power interruptions. According to them UPS allows computers to keep running for at least a short time and offer protection from power surges. This is in agreement with the study conducted by Jenkin, Webster and McShane (2011:18) that energy is wasted by using inefficient technologies and poorly designed systems.

Manually switching off computers: This was described by participants as a factor that helps in reducing or minimising environmental impact that is caused by IT use. According to the participants, this also helps in preventing computers from crashing and reduces energy consumption. They felt that this method is important because it is helping their organisations to reduce on environmental harm. Furthermore, manually switching off computers will prevent data corruption in files and crushing. Utilising this method prolongs the span of computers and conserve energy. The evidence found in the study indicates that turning off computers and printers will save energy. This is because personal computer (PC) and computers that have been switched off still draw on average 20 watts of power. Therefore, it is essential to turn off computers and peripherals when they are not in use to conserve energy. This suggests that the use of IT resources should be energy efficient and cost 
effective because the primary focus and practices of Green IT is to save energy and reduce or minimise environmental impact.

Safe disposal: According to participants, safe disposal of old pieces of equipment is an important factor to minimise harm to the environment because improper disposal of obsolete IT equipments is contributing negatively to the environment. They felt that effective and efficient procedures in managing eWaste should be developed and implemented. This finding indicates that special handling is required to dispose of and recycle computers and other hardwares. Previous studies revealed that about $80 \%$ of electronic pieces of equipment that are highly toxic are discarded in unsafe and irresponsible manner and end up in the landfills. This suggests that special measures should be developed to ensure safe disposal of e-Waste.

\section{Energy Efficient and Alternative Technologies}

Promoting energy efficiency: The participants specified that they analyse the costs that have implications to their business with the intention of improving energy efficiency because IT equipments consume lot of energy when they are not in use. They felt that it is essential for their companies to search for energy efficient products in order to reduce the business operational costs. Furthermore, they also felt that if the companies are not analysing costs this will eventually affect their financial trade-off. Therefore, analysing the business cost should be continuously evaluated and monitored.

Purchasing green products: The participants mentioned that their companies purchase/look for energy saving devices that have been manufactured in an environmental fashion. Green technology products are playing a major role in the buying process because they help their organisations to conserve the natural environment resources and lead to environmental sustainability. This lends support to previous findings in the literature that there is a need to protect the environment by adopting greener technologies. However, some of the participants mentioned that their companies were not purchasing energy saving devices.

Energy usagelefficiency: This was described by participants as the primary factor that influences their purchases. They felt that the business should find alternative ways to improve energy efficiency through designing and using 
advanced technologies to preserve the environment. It is acknowledged by Uddin and Rahman (2012:4079-4092) that energy efficient technologies can cut down the business cost significantly. This is the primary reason for computer manufacturing firms for competing and use environmentally sustainable energy efficient technologies in their products and services. This suggests that energy is a major component for economic growth in organisations. The study revealed that the wide spread adoption of green office equipment is encouraged by Energy Star which helps with the reduction of energy consumption.

Environmentally friendly/power usage/energy efficiency: This was identified by participants as an important aspect that influences purchasing because pieces of IT equipment and activities have the potential to cause irreversible harm to the environment. They felt that it should be a life style for their companies to conserve and protect the natural resources. The study revealed that organisations are becoming environmentally friendly by restricting the use of toxic and flame-retardants by the manufacturer of electrical and electronic equipment. This implies the prevention of pollution by developing and using environmentally friendly competencies with the aim of eco-sustainability (Molla \& Abareshi 2012:93).

Task specific requirements: These were described by participants as important factors that influence the purchasing pieces of IT equipment by organisations. According to the participants it is not unusual for their companies to replace old computers with new ones. This replacement of computers with new ones helps in energy conservation and preservation of the environment. The use of task specific requirements ensures that work is complete successfully. The evidence found in the study confirms that the replacement of older pieces of IT equipment with new ones is a common practice by organisations that wish to promote economic activity. This suggests that organisations are looking for ways to make their product more energy efficient which implies favouring the green concept and economic prosperity.

Greening data centres: The participants were unsure of steps that their companies should take to green their data centres and reduce operational costs. According to the participants, the data centres are consuming a lot of energy and contribute to GHG and thereby exacerbate environmental concerns. This 
finding was unexpected considering that the interview was conducted with IT professionals that were perceived to have extensive knowledge on Green IT. Gartner (2008) believes that green process should begin at data centres in order to reduce energy consumption. The underlying reason is because green is connected with the sense of environmental awareness. This suggests that organisations should strive to have efficient data centres that translate to energy savings through the use of renewable energy. In this regard, the data centres managers must consistently focus on the energy consumption and cooling issue of data centres to improve the operating costs.

Environmentally friendly data centres: These were described by the participants as an important driver for energy efficiency and alternative technology. They felt that their companies are giving less attention to infrastructural issues that consume lots of energy because it is unaffordable. Again, the participants felt that the cost of energy should be analysed in order to maximise energy efficiency and minimise environmental impact caused by data centres. It is acknowledged by literature that many data centres are more than ten years old and reaching the end of their useful life. In other words they consume a lot of electricity (Uddin \& Rahman 2012:4078). As a result, the current energy consumption in data centres is contributing to annual increase of the GHG emissions. This suggest that making data centres more energy efficient can provide financial, environmental infrastructural benefits for organisations (Widjaja, Mariani \& Imam 2011). The reason is because the world is reliant on data centres, hence the increase in power consumption.

Centralised servers: According to the participants, centralising the servers will benefit their organisations because servers consume energy even when they are idling. They felt that this will tackle environmental harm caused by IT use. This lends support to previous findings in the literature that the business needs are growing faster and the server level has increased along with performance, thus resulting in high power consumption. This implies that in order to address energy consumption it important to relocate the physical servers to virtual facilities in data centres to tackle or minimise the carbon footprint.

Server virtualisation: This was mentioned by participants as an energy efficient technology because it is important to relocate servers to virtual facilities. They felt that in a way, this will minimise potential harm to the environment and 
increase productivity. Again, the participants felt that they have limited knowledge on greening data centres hence they outsource the management of data centres to external companies. According to them, outsourcing has its own challenges for their companies as well. It is acknowledged that many server computers run less than $30 \%$ percent capacity and are more effective than average desktop machines. This implies that data energy and emission costs are a concern in green IT analysis from small installations to massive facilities with thousands of servers and tens of thousands of associated workstations. In contrast, designing energy efficient and environmentally sound components, computers, servers and pieces of cooling equipment comprehensively addresses the environmental impact of IT implying the adopting of Green IT (Chou \& Chou 2012:448).

Measures to promote energy savings: The participants mentioned that they have policies in existence that seek to promote energy savings. IT policy was stated as having the ability to articulate organisational values, strategies and providing guidance for the organisations in decision making. They felt that energy conservation translates to energy savings because IT is the driver for energy savings and innovation. In reality, IT has become the driver for energy saving and innovation. However, a large number viewed that their companies do not have IT policy while others were uncertain. They felt that their companies should make effort to develop IT policy in the most effective manner in order to promote energy savings. This is a surprising finding considering that IT policy is a fundamental tool for enforcing ecological issues, thereby ensuring organisational compliance and energy savings. This suggests that there is resistance to change for the organisation and this is one of the roadblocks to Green IT adoption.

Auditing energy consumption: This was mentioned by the participants as an important factor to minimise environmental impact. This confirms previous findings in the literature, that what get measured can be managed. Thus monitoring, analysing and reporting energy and process flows can identify best remedial efforts. In this regard, organisations should conduct energy consumption audit because energy consumption is connected to GHG emissions. This suggests that organisations should develop measures to reduce their energy consumption. The use of software programs like local cooling can calculate the electricity usage of computers and adjust the settings to minimise 
it. This implies the implementation of Green IT which can help organisations to reduce energy consumption and protect the environment (Cai, Chen \& Bose 2013:493).

Green plugs: The participants mentioned that the use of green plugs can deliver quick results for Green IT implementation. For Green IT implementation to be successful, the use of energy efficient technologies such as green plugs should be utilized. This suggests that IT is playing a significant role to conserve energy by employing green plugs and contribute to sustainable growth.

Printer reduction: This was viewed by the participants as a key element for quick wins of implementing Green IT programme. As a result of the implications of high-level energy consumption by IT activities and its contribution to GHG emissions contributing to climate change. It is recommended to consolidate printing of large number of printers into fewer central models to improve printing costs and improving energy efficiency in the use of IT devices to reduce environmental impact (Borggren et al. 2013:126).

Sensor installation: According to participants, the installation of sensors can be an improvement that is visible and can provide immediate benefits for their companies for Green IT implementation. This lends support to previous findings in literature that it is important for IT to minimise environmental impacts and maximize energy efficiency through efficient use of IT resources. This suggests that IT devices consume energy and can be used to control energy by using movement sensors. In this regard, a programme in support of energy efficiency such as fluorescent light bulbs should be launched.

LCD/LED monitors: This was viewed by the participants as contributing enormously to energy savings and contribution to their Green IT strategy. This is consistent with previous findings in the literature, that liquid crystal display (LCD) and light-emitting diode (LED) monitors and other energy efficient technology require less energy to perform their function (Uddin \& Rahman 2012:4083). It is acknowledged by literature that the new generations of products such as computers, screens and mobile infrastructure equipment have led to an average $30 \%$ power consumption efficiency gain in past years through environmentally friendly design and development. This suggests that LCD/ 
LED monitors can lead to substantial operational cost saving by reducing energy bills.

\section{Management of e-Waste}

Considering IT product life cycle upfront: This was described by the participants as an important driver during the buying process of computers and peripherals for their companies because IT product life cycle is a prerogative in the buying process for their companies. As proposed by Vereecken et al. (2010), it is important to consider material extraction, production, and use, transport and end life cycle of the IT product when determining green technology and environmental impact. This suggests that IT life cycle management promotes stewardship and value for money.

Upgrading softwares and hardwares: This was described by the participants as a factor playing a role in controlling or reducing e-waste. Replacing softwares with newer or better version in order to update the system to enhance its characteristics is a benefit for the companies. They felt that upgrading or replacing the hardware/software provides an opportunity to increase the computer performance. Again, they felt that pieces of IT equipment that are not wanted should not be discarded but refurbished or upgraded to prolong the life span. It is acknowledged by Murugesan and Molla (2011:40), that organisations' spending on software are gradually increasing because of the evolution of the digital business. As a result, old computers should be refurbished and upgraded by reconditioning and replacing some electronic parts. In this regard, Green IT implementation adresses energy consumption and waste associated with the use of hardware and software (Jenkin, Webster $\&$ McShane 2011:18). However, some of the participants mentioned that they were not really upgrading their softwares.

Hardware repair: This was viewed by participants as a way to increase the life span of hardwares that are outside warranty. According to the participants, the life span of computers is too short and most of them become obsolete. Therefore, they are used for spare parts. Then again, the participants mentioned that their companies prefer to buy new pieces of IT equipment rather than increasing the life span beyond warranty. The evidence in this study points out that computers should be upgraded and refurbished to prolong their life span 
(Murugesan \& Molla 2011:40). This suggests that the shorter life span of electronic products is posing challenges to organisations.

Auction or donation of redundant computers: According to the participants auction and donation of computers is regarded as a way to manage e-waste. This confirms the previous findings of literature, that redundant computers should be auctioned or donated (Advanced Tropical Environment 2012:96). This suggests that, e-Waste is poorly handled by organisations that do not have capacity to manage it, in terms of collection, storage, processing, destruction and disposal of non-recyclable e-Waste. It is believed by the author that auctioning and donation of redundant computers is not sufficient because it poses a further challenge of e-Waste management for the organisations receiving the donation or the buyers.

Recycling computers: This was mentioned by participants as a factor that is not utilised by their companies to prolong the life span of pieces of IT equipment and reduce on e-waste. The participants believe that their companies can recover precious metals and prevent hazardous waste through recycling. This substantiates previous findings in the literature that computer waste contributes to damaging not only the environment, but has serious consequences on human health resulting from carbon emission (Advanced Tropical Environment 2012:10-26). This implies that there is lack of adequate recycling in South Africa.

Use outsourced recycling company: The participants viewed their companies as lacking capacity to manage e-waste through recycling. Therefore, their companies have management of e-Waste to maintain focus on their core business. This confirms the previous findings in literature that the management of e-waste suffers drawbacks. This suggests that organisations are lacking waste removal infrastructure and technical capacities necessary to ensure safe disposal of e-Waste. In this regard, the incapacity of organisations on e-Waste has negative consequences on both human health and the environment.

Supplier responsible for disposal: The participants noted that they don't have the capacity to manage e-waste. Therefore, they have transferred the responsibility to the supplier to ensure safe disposal of e-Waste. They felt that their companies are utilising minimal efforts to reduce e-waste because they repair and upgrade their computers occasionally. This finding implies that organisa- 
tions should create an environmental management system that includes organisational structure, planning activities, responsibility, practice, procedure, processes and resources for developing, implementing, achieving, reviewing and maintaining environmental policy as indicated in the ISO 14001 standard to manage e-Waste. The author believes that the lack of e-waste management capacity in the organisations should be addressed to preserve the environment.

E-waste segregation: This was mentioned by participants as an important factor in disposing of any electronic equipment. According to the participants, they separate the components first before disposing of electronic equipment because discarded electronic gadgets contain harmful chemicals that have potential to contribute to environmental problems. Some of the participants mentioned that they collect segregate laptop batteries and utilise the service of external companies to collect them. Previous literature supports the segregation and recycling of e-Waste. This implies that e-Waste is not properly coordinated in organisations. In line with this finding, regulations that will make it mandatory for commercial and domestic producers of e-waste not to mix electronic waste with general solid waste should be promulgated.

Obsolete equipment returned to supplier: The participants mentioned that they return obsolete pieces of equipment to their supplier, trade them in or sell them to achieve financial returns. They felt that e-waste is posing a challenge for their organisations. This is supported by previous findings in the literature, that organisations are adopting the Switzerland system that uses the ordinance on the return and tracking back the disposal of electrical and electronic equipment. The purpose of this ordinance intended to ensure that pieces of IT equipment are disposed of in an environmentally friendly manner (Dittke 2009). This suggests that the system ensures that a person disposing of equipment shall return it to a retailer, manufacturer or importer or to a disposal facility.

ISO14001 standard: This was mentioned by participants as a system that is utilised by companies to address environmental impact. According to the participants, ISO 14001 standard helps the organisations to improve their environmental performance. ISO 14001 has the potential to help the organisations improve their environmental performance. The underpinning implementation of ISO 14001 provides a framework to foster the implementation of an environmental policy through classic management principles and the 
standard is compatible with GHG emission reduction goals.

Conformance to environmental policies: The participants mentioned that they conform to the relevant environmental policies. They felt that it is important for their companies to create an environmental system to manage their e-waste. The evidence found in the study points out that Green IT has the potential to addresses energy concerns resulting from IT activities, regulatory compliance, carbon footprint and environmental sustainability. In this regard, the adoption of Green IT will address the problem of organisations compliance with regulative, normative, cultural obligations and social responsibilities.

\section{Successful Green IT Strategies}

Management support: This was viewed as an important element for instant benefit of Green IT implementation. For the Green IT implementation to be successful organisations are encouraged to develop a culture that supports a long term approach to strategy, because the benefits of adopting Green IT are not immediate (Murugesan \& Molla 2011:41).

Research IT needs: The participants pointed out that the strategy used by their companies to address business computer needs is linked to research of IT needs. According to the participants, the strategy provides clarity and focus for their companies. This in support of literature, that investing in research and the development of advanced technologies will ensure that the business meet the requirements (Uddin \& Rahman 2012:4083). However, there is little research conducted in business today on Green IT strategy. This suggests that investing in research for IT needs is likely to impact the business performance.

Purchases must be green compliant: According to the participants, the purchases must be green compliant because they have potential benefits for the company. This confirms previous findings in the literature that organisations should comply and conform to environmental regulations. The underlying reason is because the organisations have adopted corporate social responsibility which desire to do good to the environment, achieve profitability, satisfy stakeholders and comply with governmental regulations (Molla \& Abareshi 2012:93). This suggests that purchasing should take cognisance of the IT life cycle, including the opportunities for reusing and 
recycling when the IT products reached their end of life.

Supporting green: According to the participants, green should be embraced or supported because it will provide quick wins for Green IT implementation. It is acknowledged by previous literature that one way of supporting green implies choosing more energy efficient and environmentally friendly technologies. This is because most of the technology associated with green living provides benefits to the environment.

Energy saving choices: This was identified by participants as one of the elements preferred by their organisations for successful Green IT implementation. Research studies support this finding, that IT is regarded as the driver for energy saving and innovation (Harmon \& Auseklis 2009:17011712). This suggests that energy saving choices is playing a significant role in the success of Green IT implementation.

Fax to email services: This was identified as a contributory factor for the successful implementation of Green IT. The participants viewed fax to email services as producing fruits for their companies. This finding suggests that excess copiers and fax machines should be eliminated where possible. The organisations should set fax machines so that faxes are received electronically rather than in hard copy form. Previous studies indicate that the high hopes rest upon Green IT implementation to reduce energy consumption and contribute to energy savings because it is an enabling tool for energy efficiency.

Participation of employees in Green IT implementation: It was mentioned by the participants that their companies involve them to make Green IT part of their company culture. The participants felt that Green IT implementation should be developed by engaging the relevant stakeholders. The review of literature suggests that Green strategy should be developed by engaging stakeholders (Murugesan \& Molla 2011:46). However, some of the participants felt that their companies were not involving them and are participating only to a certain extent. This implies that the lack of employee participation in Green IT implementation will have limited success.

Knowledge of IT personnel to implement Green IT: This was described by the participants as an important factor in Green IT implementation. According to 
the participants, knowledge of Green IT is vital in ensuring the success of the Green IT programme. Therefore, they felt that their IT personnel have capacity to adapt to new technologies. On the contrary, some of the participants viewed their companies having limited knowledge on Green IT. They felt that their IT personnel do not possess the necessary skills and knowledge to ensure successful Green IT implementation. According to the participants, this is inhibiting the success of Green IT implementation. This implies that the lack of knowledge of IT personnel is likely to limit the proper implementation of Green IT.

IT budget: This was described by participants as playing an important role in addressing growing computing needs. According to the participants, IT plays a central role in achieving business results. This is consistent with literature that the total global spending on IT is projected to consistently rise which indicate a new growth cycle for market research (Gartner, 2008). This suggests that the current energy costs have become a major factor for IT managers because IT equipments account for $25 \%$ of total corporate budget (Harmon \& Auseklis 2009:1708). This implies that IT budget plays a significant role in Green IT implementation.

Reliable brand choice: This was mentioned by participants as a factor contributing to the successful implementation of Green IT. In view of this finding, organisations are redesigning strategies to strengthen their brand through showcasing their initiatives and providing business opportunities.

Supplier with good technical support: This was named by participants as a specific element that their companies viewed as a successful factor for Green IT implementation. According to the participants, good technical support is beneficial for their companies for efficiency and effectiveness of their business operation. This is in agreement with previous research findings in literature that technical support and capacity is necessary to ensure efficiency of the business operation. In this regard, Green IT is regarded as a social and technical arena for innovation.

Cost effective suppliers: This was viewed by the participants as an important factor for successful Green IT strategy. As reported by Uddin and Rahman (2012:4078 - 4079), organisations are moving towards Green IT 
implementation to make their business cost effective and sustainable. This suggests that the selection of a cost-effective supplier is beneficial for the succesful implementation of Green IT.

Recruitment of IT personnel: This was viewed by participants as an instant benefit that can deliver quick results for Green IT implementation. As expected, the impact of environmental sustainability is receiving attention from IT professionals to achieve economic viability and improved business performance (Chou \& Chou 2012:448). In this regard, IT professionals are now moving towards Green IT with the aim of developing IT activities in a sustainable manner to combat environmental problems (Hanne 2011:424). This suggests that recruitment of IT personnel plays a major role in the successful implementation of Green IT.

Training: This was noted as a factor that plays a significant role in the quick implementation of Green IT. Information systems should be studied from conceptualization to development throughout the operations, in order to acquire deep understanding of IT management practices. This suggests that training will ensure successful implementation of Green IT.

IT policy: The development of IT policy was mentioned by participants as imperative to reap the immediate benefits of Green IT implementation. Studies support the use of nonrenewal resource and energy. The underlying reason being to increase economic prosperity because of the growing population. This implies the adoption of Green IT policy.

Wireless: This was mentioned as an important factor that plays a role in the quick implementation of Green IT. This is acknowledged by literature that IT should contribute in solving environmental problems through technological change and green technology. This suggests that wireless is perceived being valuable in Green IT implementation.

Aim to increase IT life span: The participants pointed out that their companies' strategy for addressing computing needs is about increasing the IT life span. They felt that IT equipments should be refurbished and upgraded to prolong their life span. This is in agreement with previous findings of literature that since the lifespan of IT products are very short, they should be refurbished, re- 
used or recycled in order to prolong their life span. This suggests that increasing life span of IT equipments is logical to address computing needs within the organisations.

Replacing legacy equipment: According to participants, clear processes and standards are required when replacing legacy equipment. They felt that this is beneficial for the successful implementation of Green IT for their companies. It is acknowledged by studies that IT is contributing to environmental problems because of the increased number of computers and their frequent replacement (Uddin \& Rahman 2012:4081). This implies putting measures and clear processes in place to replace legacy equipment with new computers.

Reuse IT equipments: According to participants, the company reuses all IT equipment as far as possible in order to address computing needs. They felt that IT equipment should be reused to ensure more efficiency of resources and provide business solution for growing computing needs. This confirms the previous findings of the literature, that efficient use of resources is important for organisations through reuse of pieces of IT equipment. In this regard, organisations should be encouraged to reuse, remanufacture and recycle IT used products in order to reduce harmful effects to the environment. This suggests that reusing IT equipment provides plausible benefits for computing needs.

Vendor management fitting into business strategy: This was described by participants as a factor that will lead to competitive advantage for their business. This will help the companies to develop strategic plans that are based on long term objectives leading to financial benefits and environmental sustainability. This lends support to previous findings in literature that there is a real, economic imperative to change and improve organisations environmental credentials. The underlying reason is that the investors are beginning to demand more disclosures from companies with regard to their carbon footprint, as well as their environmental initiatives and achievements. In this regard, manufacturers are improving their processes at all the life stages to minimise harm by employing cleaner technologies. Furthermore, they also provide environmental information that organisations can use to make buying choices (Gartner 2008). On the contrary, some of the participants were uncertain about their vendor system fitting into the business Green IT strategy. According to the participants, this is an element of deficiency in managing the 
vendor. Organisations should have green visions and strategic plans that are based on long term objectives for environmental sustainability. This implies that the Green IT strategy should be aligned with the business strategy to enhance organizational competitiveness and managing environmental aspects.

\section{Summary of the Study}

From the analysis of the interviews, a number of issues emerged with regard to factors that inhibit the Green IT implementation. The interview revealed that ecological issues, lack of training on policies and regulations, unstructured and uncoordinated green IT implementation, limited knowledge to green data centres, too much outsourcing, incapacity to recycle, improper e-waste disposal, lack of e-waste legislations, limited knowledge of IT personnel, inadequate involvement of employees and poor vendor management are hampering the implementation of Green IT.

\section{The Main Findings \\ Demographics}

It is evident and undisputable that the IT personnel have the necessary knowledge, experience and competency. However, this study has revealed that they have limited knowledge of Green IT. As a result, this can possibly impede the acceleration of Green IT implementation within their organisations.

\section{Ecological Issues Caused by IT Use}

In line with the findings, it was quite interesting to note that some of the participants did not regard their companies as making efforts to protect the natural environment that is affected by IT operations. The author contends that from this perspective, there seems to be ignorance about the benefits that can be derived from Green IT. This means that the companies will continually contribute to the disproportionate burden of environmental degradation.

\section{Energy Consumption Caused by IT Equipments}

The results identified that some of the companies were not analysing their energy costs while others indicated that their companies were not purchasing 
energy saving devices. Therefore, it is highly unlikely that Green IT will be successful without reducing energy consumption. If attempts are not made to reduce energy consumption, this situation will worsen, unless it is continuously evaluated and monitored. In view of the findings on energy consumption, it was further discovered that the participants were relying on paper copies hindering the success of going green because excessive printing hit on energy cost and further cause significant harm to the environment. Therefore, printing reduction was suggested by participants because they derived some benefits from Green IT implementation, especially on energy cost.

\section{Limited Knowledge to Green Data Centres}

The study revealed that the organisations are uncertain of the steps that they should take to green their data centres. Notably, the participants indicated that data centres were consuming a lot of energy and contributing to GHG as a result exacerbating environmental concerns. In view of this evidence, some of the participants indicated that their organisations were not taking steps to green their data centres. The participants were of the opinion that their companies were giving less attention to infrastructural issues that consume energy. It is believed by the participants from the evidence presented that the servers and data centres are hitting hard on energy even when they are idling. In a nutshell, the study revealed that the organisations have limited knowledge of green data centres hence they outsource the management of data centres to external companies.

\section{Improper e-Waste Disposal}

The study revealed that the participants preferred to buy new IT equipment rather than increasing the life span beyond warranty. They also use an external company for disposal of their e-waste. On the contrary, the evidence revealed that the participants viewed the cost of repairs being expensive as a result they are not upgrading and refurbishing their IT equipment to prolong their life span. The evidence from the study suggests that the organisations have limited knowledge on the disposal of obsolete electronic equipment. As a result, it is posing a challenge to their organisations. This clearly demonstrates lack of capacity to manage e-waste in the organisations. 


\section{Incapacity to Recycle}

From the evidence presented in the study, the participants indicated that recycling, refurbishing and repairs of computers in order to extend the life cycle of electronic products playing a role in ensuring IT operations compliance. Surprisingly, some of the participants indicated that they were not recycling and their companies were lacking the capacity to manage e-waste.

\section{Lack of e-Waste Legislations (Policies/Regulations)}

The study revealed that some of the participants were uncertain about the policies and regulations to mitigate the harmful impact that is caused by IT use. In the same light, the participants indicated that there was lack of formal penalty and the regulations were not enforceable to ensure handling and safe disposal of e-waste. The evidence presented by this study suggests poor legislation on e-waste to protect the environment and improve the quality of life. In the same wavelength, the participants were of the view that there was lack of awareness among staff members because policies and regulations were not publicly available. Surprisingly, the participants revealed that they were not ensuring compliance because there was insufficient legislation dealing with e-waste. They also revealed that government policies were inadequate and being reactive rather than proactive. It should be noted that the purpose of the legislation is to provide a governing framework to protect the environment and hold organisations accountable. This evidence is classic demonstration that there is lack of policies/regulations within the organisations.

\section{Lack of IT Policy Impeding Green IT Implementation}

The study revealed that the companies do not have IT policies in order to promote energy savings. In theory, it should be noted that IT policy is beneficial for the company to protect it from external threats. In light of the above statement, the present evidence indicates that Green IT implementation is hindered.

\section{Unstructured and Uncoordinated Green IT Implementation}

The evidence provided by the study revealed that the participants believe in Green IT as an investment for their companies. However, quiet shockingly the 
participants mentioned that their organisations were not focusing on green or energy savings. They highlighted that their purchasing does not take into consideration the green aspects. In light of this finding, a further blow was that some of the participants indicated that their companies were not going green because they did not derive any value from Green IT adoption. Furthermore, the evidence showed that there are no factors that are driving Green IT adoption. This clearly indicates that there is limited understanding of Green IT. On the other hand, some organisations indicated that because their suppliers were green, it automatically meant they were going green as well, while others mentioned that their organisations were not purchasing energy saving devices. Again, the participants pointed out that their organisations were not considering IT product life cycle when procuring computers. This is a classic illustration that there is lack of knowledge for Green Information Technology (IT) implementation.

\section{Lack of Defined Green IT Strategy and Poor Vendor Management}

It was interesting to note that the participants revealed that there is no strategy in the organisation to drive growing computing needs. Remarkably, some of the participants revealed that their companies were not conducting research before purchasing. Similarly, some of the participants were of the view that Green IT strategy did not match their business requirements. A clear picture from the results designates that there is lack of strategy and poor vendor management.

\section{Limited Knowledge of IT Personnel}

It was interesting to note that some of the participants pointed out that their IT operations did not contribute to environmental harm. They regarded their companies as making efforts in ensuring reduction or elimination of sensitive materials resulting from IT products that influence the environment by utilising various methods of technology. Shockingly, some of the participants were of the opinion that their companies had limited knowledge on Green IT implementation. The present evidence indicates that the IT personnel have limited knowledge of Green IT. 


\section{Limited Involvement of Employees on Green IT Implementation}

The participants mentioned that their companies involved them in making Green IT part of their culture. In contrast, some of them revealed that their companies were not involving them in Green IT implementation. The study also revealed that employees were not adequately involved in Green IT implementation.

\section{Inadequate Training of Employees and Managers on Green IT}

The study revealed that the staff were not adapting to their work habits without supervision because they were inadequately trained. In the same way, the participants indicated that they were not provided with training on policies and procedures. Therefore, this is collapsing their Green IT strategy. The evidence presented indicates that there is lack of training regarding Green IT. Moreover, the evidence presented also acknowledged that employees and managers were not adequately receiving appropriate training regarding the measures that should be instituted to reduce/minimise energy consumption that is caused by IT operation. The success of Green IT depends on how well the employees perform. Without training the organisations will not be able to attain their goals in improving energy efficiency. Lack of personnel skills development unfavourably impacts the company success for Green IT implementation.

\section{Too Much Outsourcing of IT Operations}

The study revealed that some of the organisations were outsourcing some of their activities to external companies in order to reduce the cost of doing business and focus on their core business. However, some were discontented that too much outsourcing was impeding Green IT strategy and posing a challenge to their organisations because they did not have proper control. This indicates that outsourcing has potential benefits and challenges for the organisations.

\section{Developing Framework for Green IT}

The research objectives have been addressed by the findings and supported by literature. The framework is based on the findings that have been statistically 
Tlhalefo Petterson Moyo, Sam Lubbe, Rembrandt Klopper \& Jan Meyer

developed and tested. The findings have highlighted that the primary drivers for Green IT are the following:

Green IT drivers

- Environmental concerns

- Cost reduction

- Company image

- Competition

- Corporate social responsibility

Impact of IT related products on the environment and health

- Pollution

- Carbon emission

- Ecological issues

- Environmental degradation

- Climate change

Development and implementation of Green IT into business strategic plans

- Management support

- Conducting research

- Green compliance

- Energy saving choices

- Participation and knowledge of employees

- IT Budget

- Reliable brand choice

- Cost effectiveness and technical support

- Recruitment of IT personnel

- Training on policies and procedures

- Increasing the life span of IT equipment

- Vendor management

Evaluating the approach to Green IT

- Promoting energy efficiency

- Purchasing green products

- Energy usage/efficiency 
- Task specific requirements

- Greening data centres

- Centralised servers

- Server virtualisation

- Auditing energy consumption

- Green plugs

- Printer reduction

- Sensor installation

E-waste management

- Considering IT product life cycle upfront

- Upgrading software's and hardware's

- Repair/upgrade

- Auction or donation of computers

- Reuse and recycle

- E-waste segregation

- Return to supplier/Trade

- Safe disposal

- Conformance to environmental policies

Measures that can be used by organisations to implement Green IT

- Green products purchase

- IM communication

- Bio plugs

- Safe disposal

- Printing reduction

- Use of UPS and generator

- Manually switching off computers

- IT policy

\section{Green IT Framework}

Green IT framework is an essential supporting structure that ensures a practical approach for successful Green IT implementation. In other words, it provides guidelines that can be used or modified for Green IT implementation. Figure 1 displays the Green IT Framework. 
Tlhalefo Petterson Moyo, Sam Lubbe, Rembrandt Klopper \& Jan Meyer

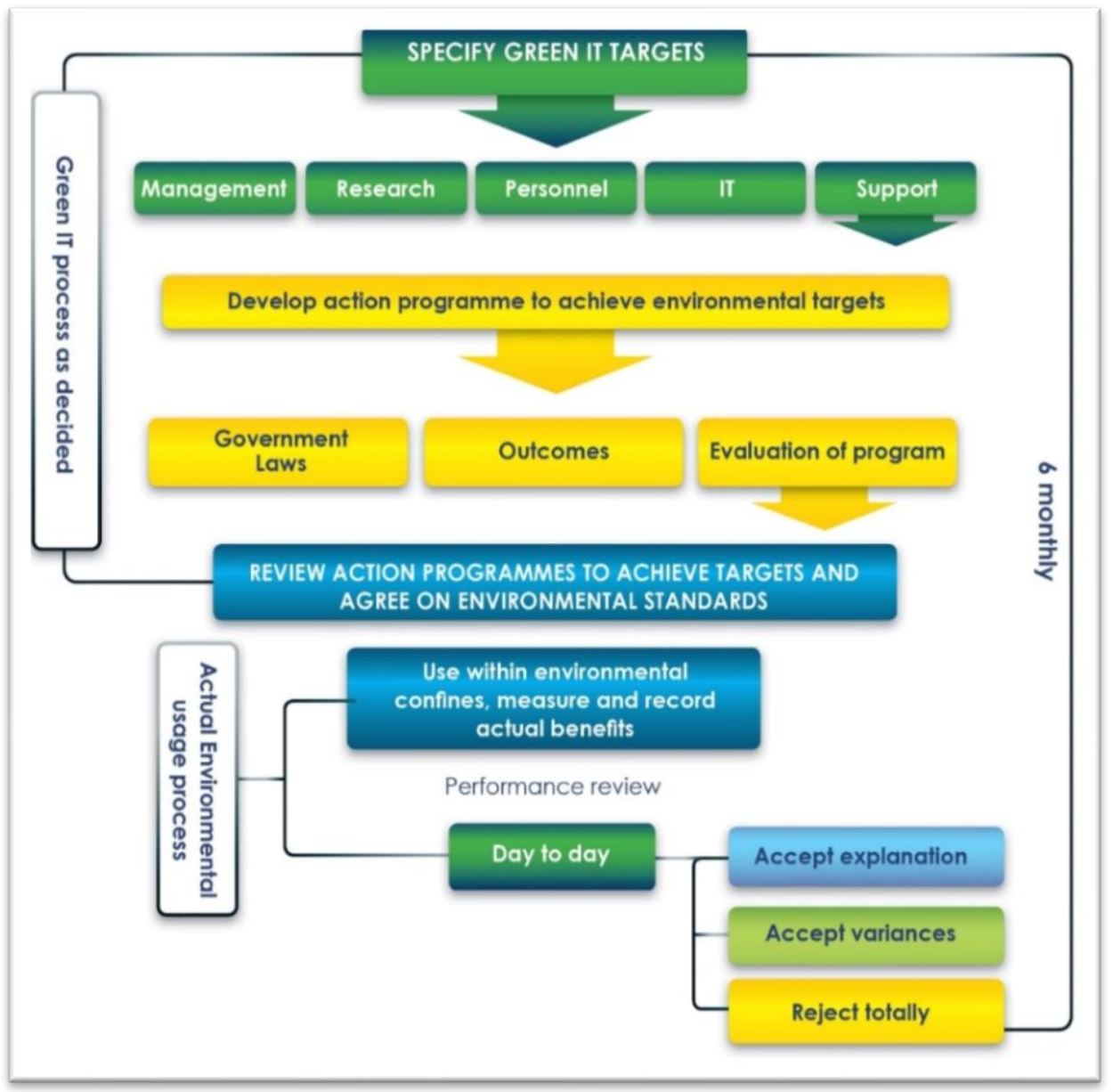

Figure 1 Green IT Framework

\section{Process Flow of Green IT Implementation}

This process flow is a method that documents the stages that should be involved in implementing Green IT. It is a flow chart that shows inputs or information that is followed by each step to create deliverable output of Green IT implementation. Figure 2 displays the process flow that should be followed by organisations to ensure successful Green IT implementation. 


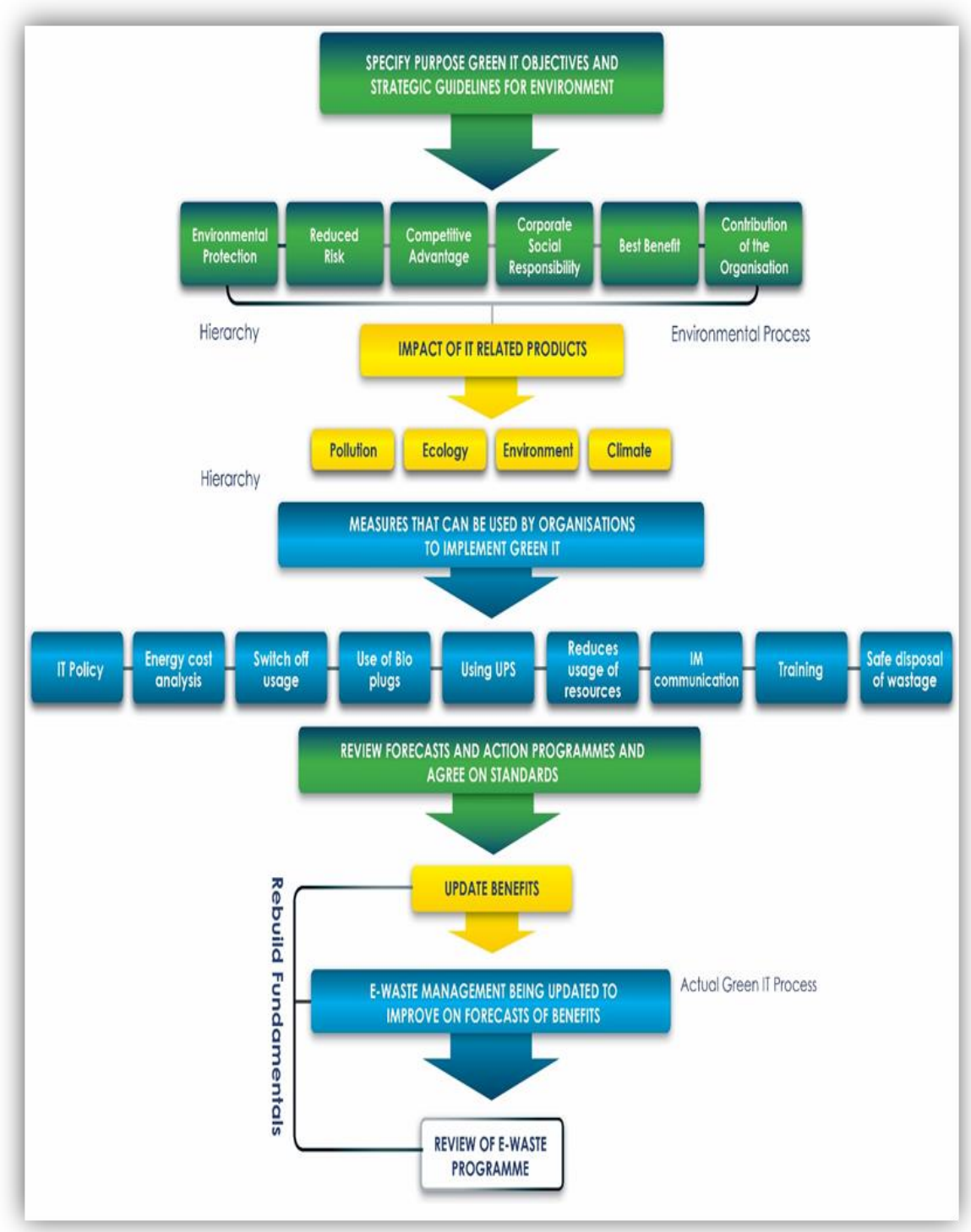

Figure 2 Process flow of Green IT implementation 


\section{Proposed Framework}

The proposed framework displays a new approach to the implementation of Green IT. This framework provides a direction, illustrates evolutionary paths, and depicts necessary changes and practical application of Green IT implementation. Furthermore, ensures that organisations respond to environmental sustainability in a proactive manner, prevent waste of resources and poor return on investment. In the ultimate, it provides guidance for organisations about how to implement Green IT and leverage IT for environmental sustainability. Figure1, exhibits the specification of Green IT targets that could be used in the Green IT implementation. This target contains two processes namely, environmental process and the actual Green IT process. The environmental process starts with a specification of Green IT objectives and strategic guidelines for the environment. The objectives in this framework could be achieved by setting one or combination of the reasons named by participants in this study. The next process during the Green IT implementation process is the development of action programmes to achieve the IT investment targets. The Green IT implementation process involves finalising the expected standard performance in terms of the previously agreed upon action programme before using IT. This implies that the user should record actual benefits as Green IT is being implemented, compare the actual benefit with expected standard on a daily basis and any discrepancies should be noted. In this framework, on a six monthly basis a major review of Green IT process targets should be undertaken, at which stage new targets will be set. However, Green IT targets will keep on changing because the IT keeps on evolving. The possibility is that Green IT process objectives may not be reached as a result of these gradual changes. This mean that the Green IT process action plans should thus include the following strategies: accept explanations for the differences (variances) between actual Green IT benefits and the benefit standard agreed upon. This suggests that no changes are thus made to the Green IT targets and actual environmental usage process. In order to accept the variances in light of the changed circumstances new targets will have to be reviewed and new actual environmental usage process goals should be set. This process will thus start all over again. The last part on the Green IT framework could be a drastic decision whereby the superior decides to reject the Green IT implementation totally, set new targets and specifies as new Green IT action plan, starting the process all over again. 


\section{Process Flow of Green IT Implementation}

From the analysis of the interviews, a number of issues emerged with regard to factors that inhibit Green IT implementation. In Figure 2, action program that can provide assistance with the evaluation of the proposed Green IT implementation is developed. Upon the development of this action programmes, a commitment to achieve the Green IT target is required from the organisations. Furthermore, the Green IT benefits identification during the Green IT process implementation and Actual usage phases is demonstrated. This process of Green IT benefit specification seems appropriate for the organisations. The process flow demonstrates the important process of Environmental process management. In this regard, top level management should specify benefit purpose and strategic guidelines for the Green IT implementation process using the IT benefit themes identified by participants in the study. The objectives and strategies for Green IT implementation could specify one or more benefit for all the themes. This implies that the management could develop forecasts or the benefits expressing simultaneously to what extent it could affect the Green IT implementation in the organisation. Thus, action programme could then be developed to help achieve the management to review the forecast and action programmes and agree on accepted levels for the Green IT benefits that should realised. The relevant stakeholders will eventually have to rebuild fundamentals that are required to achieve the benefits agreed upon by top management. As Green IT is implemented, action programmes need to be improved and the forecast level of benefits adjusted. In the ultimate end, these actions would require involvement of management before, during and after the Green IT implementation process.

\section{Recommendations}

For the results of this study, the following guidelines are given to the organisations in order to ensure that they reap the benefits of Green IT implementation in the future:

\section{Ecological issues}

- Green products that are certified should be purchased to enhance a sense of environmental awareness and economic development. Environmentally friendly goods that meet stringent energy efficiency 
standard such as EPEAT are less harmful to human health and environment.

- IM Communication such as teleconference, Skype, Lync or Videoconference call should be utilised to reduce travelling. This will allow people working far away from each other to interact. This type of communication allows paperless communication as well and it will reduce carbon emission caused by vehicles leading to environmental pollution.

- Printing should be reduced because it causes significant environmental harm due to the cutting of trees to manufacture printing paper. Therefore, double sided print out should be implemented and the organisations should consider going digital. This has the potential to reduce the energy costs by $30 \%$. Also, the printing configurations should be changed to use less paper and ink.

- Electronic equipments should be disposed of safely because they contain hazardous material that does not belong to the landfills.

- Environmental laws should be complied with to address environmental pollution that is caused by IT use.

- Outsource data centre management to experts that will provide solution to solve pressing data management issues.

\section{Energy Consumption}

- Use natural resource to reduce energy consumption and pollution to the atmosphere.

- Energy cost should be analysed to determine the usage of energy by IT equipments in order to reduce energy costs.

- Audit energy consumption in order to provide the organisation with accurate information on how they can reduce energy consumption and save energy costs.

- Procure energy efficient products to reduce energy loads, increase cost effectiveness and resource conservation.

- Computer power that is on all the time can shorten its life span. Therefore, manually switching off computers is recommended to promote energy savings.

- The use of bio plugs can help the organisations to reduce energy bills and eventually saving energy. 
- Promote training and awareness on energy efficiency to encourage energy savings.

\section{Limited Knowledge to Green Data Centres}

- Energy cost should be analysed to determine the usage of energy by data centres in order to reduce the cost of energy.

- Green the data centres to maximise their energy efficiency and minimise their environmental impact.

- Attention should be given to infrastructure to facilitate, manage and enable efficient data centres.

- Use server virtualisation to allow one physical server to be used into a multiple isolated virtual environment to reduce energy consumption.

- Servers should be centralised to connect to a central server which will act as agent for all communications.

- Outsource data management to expert companies to help in the management of data centres.

- Consider using cloud computing to remote server's hosted environment rather than using local servers.

\section{Ineffective e-Waste Management}

- Green product should be purchased to enhance a sense of environmental awareness and economic development because environmentally friendly goods are less harmful to human health and environment.

- Consider IT product life cycle upfront because understanding the IT life stages helps to get the longest possible life span out of a product and the organisation can receive return on investment.

- Focus on buying IT equipments with good quality and that are reliable to reduce on the frequency of e-waste.

- Upgrade hardwares and softwares to extend the life span of computers and enhance computer version.

- Reuse and recycle IT electronics ensuring separation at the source, reducing e-waste. This is the most effective method to manage ewaste.

- Repair and upgrade IT equipments to increase their life span.

- Segregate e-waste before disposal for proper disposal and recycling. 
- Return obsolete IT equipments to the supplier to ensure safe disposal.

- E-waste should be reduced and disposed of safely to eliminate hazardous material at licenced dumping sites.

\section{Incapacity to Recycle}

Ensure that recycling of electronic devices is conducted to reduce e-waste. Obsolete computers and electronics are valuable sources for secondary raw materials if recycled; otherwise these devices are a source of toxins and carcinogen.

\section{Fragmented and Ineffective Policies and Regulations}

- Efforts should be made to ensure regulatory compliance with the policies and regulations due to poor regulatory controls. The available policies and regulations should be enforced.

- Organisations should partner with governmental stakeholders to pursue the development of sufficient legislation on e-waste to protect the environment.

- Internal and external audits should be conducted to improve the organisations' IT operations and ensuring compliance with environmental laws.

- ISO 14001 management system should be implemented to ensure compliance with standards monitoring and reporting tangible improvement in sustainable use of natural resources.

\section{Lack of IT Policy}

Develop IT policy to guide the employees and ensure environmental protection and security of networks and information resources. Ensure IT policy is administered in the most efficient and effective manner. The policy should include the prevention, reduction and control of pollution of any of IT use causing harm to the environment.

\section{Unstructured and Uncoordinated Green IT Implementation}

Green IT should be approached by purchasing green products that are certified and energy efficient during their life time and recyclable. Utilise the Green IT framework for the approach. Competency of IT personnel should be developed through the attendance of workshops, symposia, seminars and conferences. 


\section{Poor Vendor Management}

- A clear detailed action plan should be developed by suppliers to address environmental problems caused by IT use by assigning responsibilities, allocating resources, monitoring and regulating actions and measuring evaluation of outcomes.

- Conduct research to identify IT needs.

- Match IT system to business requirements for the successful implementation of Green IT. Formulate the requirements to ensure that the supplier provides useful IT related materials to the organisation.

- Provide sufficient IT budget to acquire green technology systems that are environmentally friendly.

- Management support is required for the successful implementation of Green IT strategy.

- Obtain a supplier with good technical support to solve specific IT problems and provide assistance to accelerate the Green IT process.

- Procure from a cost effective supplier to ensure affordability of the Green IT process.

- Ensure proper vendor management to ensure that relationships exist to ensure that agreements are mutually beneficial for both parties. Select a vendor that will match the company performance. Impose green requirements on the supplier and demand sustainability report.

- Develop Green IT strategy to meet the operational requirements for function ability of IT and environmental protection.

\section{Limited Knowledge of IT Personnel}

Develop capacity of IT personnel by ensuring that they attend workshops, seminars, symposia and conferences that are related to Green IT to keep abreast with the latest developments and expand their knowledge.

\section{Inadequate Involvement of Employees}

- Involve/engage stakeholders in order to contribute to the effective and informed decision making of Green IT implementation. Employee involvement will ensure that the objectives of Green IT are fulfilled.

- Increase participation of employees in environmental management to maintain and improve quality of life. 
- Disseminating meaningful information about Green IT through awareness campaigns ensures better understanding of Green IT concept for successful implementation.

\section{Lack of Training of Employees}

- Train employees and managers on Green IT strategy to improve and enhance knowledge of Green IT concept. Training will contribute to the successful implementation of Green IT.

- Train staff on environmental impact that is caused by IT use to improve and enhance knowledge of employees on environmental issues that are caused by IT use.

- Create an awareness and understanding of environmental issues to employees. This will ensure that employees contribute significantly to the protection of the environment from harm caused by IT use.

\section{Too much Outsourcing}

Reduce outsourcing of many IT activities to ensure proper control. Outsourcing is a threat to security and confidentiality. It is also associated with hidden costs and loss of control because it is tied to the wellbeing of another company.

\section{Conclusion}

The aim of this paper was to develop a Green IT framework for South African organisations. This study sheds light on possible solutions for successful Green IT implementation with South African organisations. The authors believe that the study makes a contribution to identify and provide remedial action on the challenges relating to managing carbon emission through efficient use of IT technologies. The paper is of value to the IT personnel and management in organisations. Green IT is at the forefront of technological civilisation. Therefore, business and society do not have to become victims of their own opulence. After an extensive research of this study, a research gap was identified on ecological issues, lack of training on policies and regulations, unstructured and uncoordinated green IT implementation, limited knowledge to green data centres, too much outsourcing, incapacity to recycle, improper ewaste disposal, lack of e-waste legislations, limited knowledge of IT personnel, 
inadequate involvement of employees and poor vendor management have been identified as factors that are impeding the implementation of Green IT. The study has addressed these research problems by developing a Green IT framework that explicates the enabling capability of Green IT for environmental sustainability. The proposed new Green IT framework in this study will provide business with enormous benefits such as reduction on energy and business cost that will translate into financial returns, environmental protection, human health and wellbeing protection and ensuring corporate social responsibility.

\section{References}

Adhikary, R. 2008. The Promise of Green Design. Design Management Review Fall 2008: 22-29.

https://doi.org/10.1111/j.1948-7169.2008.tb00137.x

Advanced Tropical Environment (ATE) 2012. Identification of the Magnitude of the Electrical and Electronic (E-Waste) Situation in South Africa: A Strategic Approach to International Chemical Management (SAICM) Ewaste as an Emerging Policy Issue. Pretoria: Department of Environmental Affairs.

Beluz, J., B. Plumer \& B. Resnick 2016. The 7 Biggest Problems Facing Science, according to 270 Scientists. Available at:

https://www.vox.com/2016/7/14/12016710/science-challeges-researchfunding-peer-review-process (Accessed on 22 May 215.)

Berghout, E., M. Nijlan \& P. Powell 2011. Management of Life Cycle Costs and Benefits: Lessons from Information Systems Practice. Computers in Industry 62,7,September: 755 - 764.

https://doi.org/10.1016/j.compind.2011.05.005

Binns, S., E. Kretzmanb, M. Kurpiewski, S. Lee, S. Carlson, A. Marke, C. Reilly, S. Senefelder, S. Wade, S. Wilson \& S. Cohen 2006. Electronic Waste Recycling Promotion and Consumer Protection Act. Available at: http://www.columbia.edu/cu/mpaenvironment/pages/projects/summer06/ ewastefinalReport.pdf

(Accessed on 24 March 2015.).

Borggren, C., S. Moberg, M. Rasanen \& G. Finnveden 2013. Business Meeting at a Distance - Decreasing Greenhouse Gas Emissions and Cumulative 
Tlhalefo Petterson Moyo, Sam Lubbe, Rembrandt Klopper \& Jan Meyer

Energy Demand? Journal of Cleaner Production 41: 126 - 139. https://doi.org/10.1016/j.jclepro.2012.09.003

Bourke, B. 2014. Positionality: Reflecting on the Research Process. The Qualitative Report 19,33: 1 - 9.

Brooks, S., X. Wang \& S. Sarker 2012. Unpacking Green IS: A Review of the Existing Literature and Directions for the Future. In Vom Brocke, J., S. Seidel \& J. Recker (eds.): Green Process Management: Towards a Sustainable Enterprise. Heidelberg, Dordrecht, London, New York: Springer. Available at: https://doi.org/10.1007/978-3-642-27488-6_2

Cai, S., X. Chen \& I. Bose 2013. Exploring the Role of IT for Environmental Sustainability in China: An Empirical Analysis. International Journal of Production Economics 146: 491 - 500.

https://doi.org/10.1016/j.ijpe.2013.01.030

Campbell, W.M., M. Ratcliffe \& P. Moore 2013. An Exploration of the Impact of Organisational Culture on the Adoption of Green IT. IEEE International Conference on Green Computing and Communications and IEEE Internet of Things and IEEE Cyber, Physical and Social Computing. Available at: https://www.semanticscholar.org/paper/An-Exploration-ofthe-Impact-of-Organizational-on-Campbell-

Ratcliffe/88dfd90ae09dc52ac2f0bf40b5834e6f86051bb0

Chou, D.C. 2013. Risk Identification in Green IT Practice. Computer Standards and Interfaces 35: 231 - 237.

https://doi.org/10.1016/j.csi.2012.10.001

Chou, D.C. \& A.Y. Chou 2012. Awareness of Green IT and its Value Model. Computer Standards and Interfaces 34,1: 447 - 451.

https://doi.org/10.1016/j.csi.2012.03.001

Chow, W.S. \& Y. Chen 2009. Intended Belief and Actual Behaviour in Green Computing in Hong Kong. Journal of Computer Information Systems 50,2: $136-141$.

Clarke, A. 2011. An Invitation to Social Research: How it's Done. $4^{\text {th }}$ Edition. New York: Wadsworth Cengage Learning.

Christensen, L.B., R.B. Johnson \& L.A. Turner 2011. Research Methods, Designs and Analysis. $11^{\text {th }}$ Edition. Boston-USA: Pearson.

Dao, V., I. Langella \& J. Carbo 2011. From Green to Sustainability: Information and an Integrated Sustainability Framework. Journal of Strategic Information Systems 20,1: 63 - 79. https://doi.org/10.1016/j.jsis.2011.01.002 
Dittke, M. 2009. A Review of South African Environmental and General Legislation Governing e-Waste. Cape Town: Electronic Waste Association of South Africa.

Gaidajis, G., K. Angelakoglou \& D. Aktsoglou 2010. E-waste: Environmental Problems and Current Management. Journal of Engineering Science and

Technology Review 3,1: 193 - 199. https://doi.org/10.25103/jestr.031.32 Hanne, F.Z. 2011. Green IT: Why Developing Countries Should Care. International Journal of Computer Science 8,1: 424 - 427.

Harmon, R.R. \& N. Auseklis 2009. Sustainable IT Services: Assessing the Impact of Green Computing Practices. Portland: Picmet Proceedings. https://doi.org/10.1109/PICMET.2009.5261969

Jenkin, T.A., J. Webster \& L. McShane 2011. An agenda for Green Information Technology and Systems Research. Information and Organisations 21,1: 17 - 40.

https://doi.org/10.1016/j.infoandorg.2010.09.003

Kiddee, P., R. Naidu \& M.H. Wong 2013. Electronic Waste Management Approaches: An Overview. Waste Management 33: 1237 - 1250. https://doi.org/10.1016/j.wasman.2013.01.006

Korte, M., K. Lee \& C.C. Fung 2012. Evolving IT Management Frameworks Towards a Sustainable Future. In $21^{\text {st }}$ International Conference of Information Systems Development, Murdoch University, Prato: Italy. https://doi.org/10.1007/978-1-4614-7540-8_21

Lee, S.M., S. Park \& S. Trimi 2013. Greening with IT: Practices of Leading Countries and Strategies of Followers. Management Decision 51,3: 629 642. https://doi.org/10.1108/00251741311309698

Leedy, P.D. \& J.E. Ormrod 2013. Practical Research - Planning and Design. $10^{\text {th }}$ Edition. Boston: Pearson.

Li, Y. 2017. Resource Allocation in a Cloud Partially Powered by Renewable Energy Sources. Distributed, Parallel and Cluster Computing. Available: https://tel.archives-ouvertes.fr/tel-

01595953/file/2017IMTA0019 LiYunbo.pdf (Accessed on 11 October 2017.)

McNabb, D. 2010. Research Methods for Political Science: Quantitative and Qualitative Approaches. $2^{\text {nd }}$ Edition: New York. M.E. Sharpe.

Mingay, S. \& A. Rowsell-Jones 2008. The CIO's Role in Enterprise wide Environmental Sustainability. International Journal of Computer Science Issues 8,4: 424 - 427. 
Molla, A. 2009. Organisational Motivations for Green IT: Exploring Green IT Matrix and Motivation Models. Pacific Asia Conference on Information Systems (PACIS). School of Business Information Technology, RMIT University - Melbourne, Australia.

Molla, A. \& A. Abareshi 2012. Organisational Green Motivations for Information Technology: Empirical Study. Journal of Computer Information Systems 52,3: 92 - 102.

Murugesan, S. 2008. Harnessing Green IT: Principles and Practices. IT Professional 10,1: 24 - 33. https://doi.org/10.1109/MITP.2008.10

Murugesan, S. \& P. Molla 2011. On Harnessing Green IT and Cloud Computing. SETLabs Briefings 9,1: 39 - 48.

Murugesan, S. 2013. How Green is IT? Available at:

http://www.computer.org/portal/web/computingnow/achieve/april2013.

(Accessed on 07 March 2018.)

Nayab, N. 2011. Concept of Green Technology: How it all Began. Available: https://www.brighthub.com/environment/green-

computing/articles/71176.aspx (Accessed on 04 April 2018.)

Petzer, C., C. McGibbon \& I. Brown 2011. Adoption of Green IS in South Africa: An Exploratory Study. Paper presented at the South African Institute of Computer Scientists and Information Technologists (SAICSIT) Conference, Cape Town, South Africa.

https://doi.org/10.1145/2072221.2072270

Roosa, S.A. \& A.G. Jhaveri 2009. Carbon Reduction: Policies, Strategies and Technologies. Lilburn, GA: The Fairmont Press.

Schiffman, S. 2015. The Impact of Green Management and Technology in the Electrical and Electronics. Available at:

https://www.researchgate.net/publication/283799597_The_impact_of_gr een management and technology in electrical and electronics manuf acturing_in_business_sustainability_in_Malaysia (Accessed on 22 May 2016.)

Uddin, M. \& A.A. Rahman 2012. Energy Efficiency and Low Carbon Enabler Green IT Framework for Data Centres Considering Green Metrics. Renewable and Sustainable Energy Reviews 16: 4078 - 4094. https://doi.org/10.1016/j.rser.2012.03.014

Vereecken, W., W. van Heddeghem, D. Colle, M. Pickavet \& P. Demeester 2010. Overall ICT Footprint and Green Communication Technologies. Ghent: Ghent University. 
https://doi.org/10.1109/ISCCSP.2010.5463327

Widjaja, N.D., M. Mariani \& K. Imam 2011. IT Professional Awareness: Green IT International Comparison Study. Communication of the IBIMA. Jakarta, Indonesia: Binus International University.

https://doi.org/10.5171/2011.534852

Tlhalefo Petterson Moyo

North West University

tpmoyo76@gmail.com

Sam Lubbe

Faculty of Management Sciences Mangosuthu University of Technology

Umlazi

South Africa

Lubbe.samuel@mut.ac.za

Jan Meyer

NWU Business School

North West University

Mafikeng

South Africa

Jan.meyer@new.ac.sa

Rembrandt Klopper

Department of Communication Science

Faculty Arts

University of Zululand

South Africa

rklopper@gmail.com 